\title{
CATHODE STRIP CHAMBER INTERFACE WITH SUPPORT STRUCTURE FOR SSC GEM DETECTOR MUON SUBSYSTEM
}

F. C. Belser, J. W. Clements, F. R. Holdener,

J. A. Horvath, S. M. Pratuch, C. R. Wuest

Lawrence Livermore National Laboratory, Livermore, CA

F. Nimblett, J. Paradiso, P. Sebelius

Charles Stark Draper Laboratories, Cambridge, MA

J. Antebi, R. P. Ojdrovic, M. S. Zarghamee

Simpson Gumpertz \& Heger Inc., Arlington, MA

M. Marx

State University of New York, Stony Brook, NY

C. V. Johnson, G. Mitselmakher

Superconducting Super Collider Laboratory, Dallas, TX

December 8, 1993

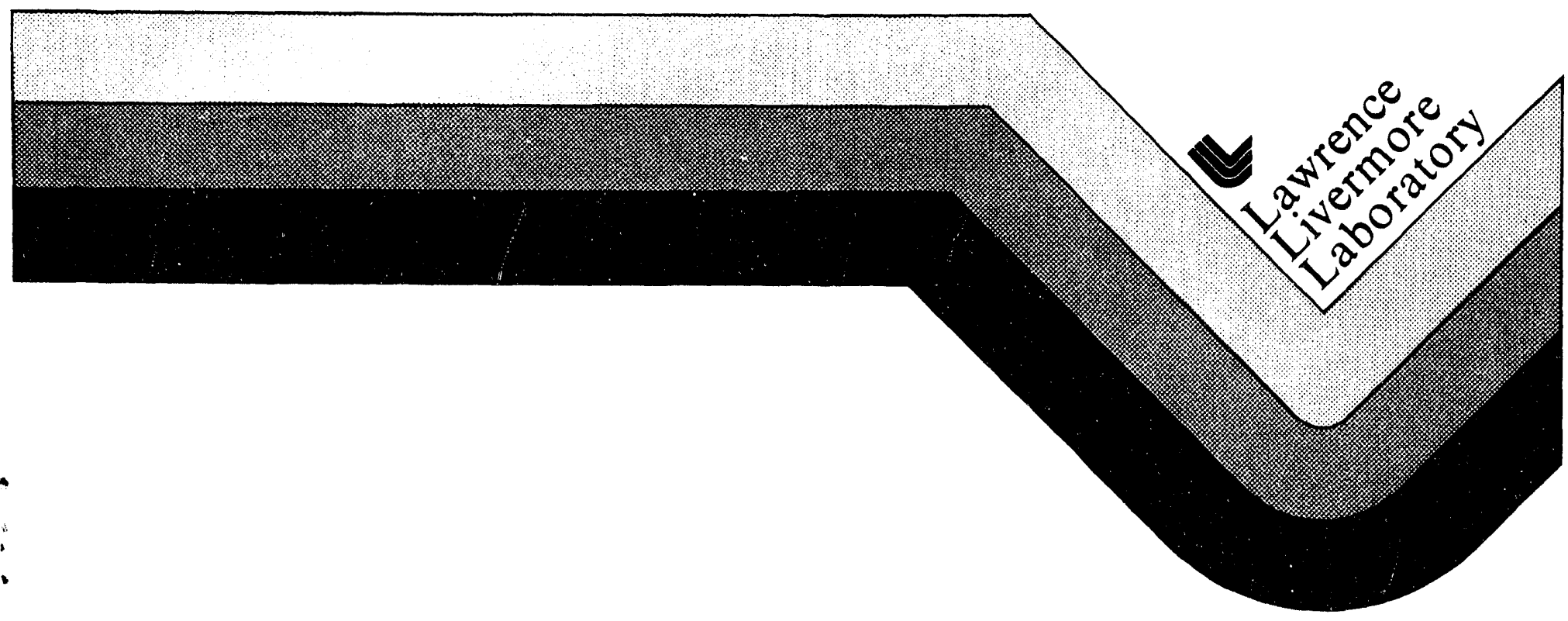


DISCLAIMER

Work performed under the auspices of the U.S. Department of Energy by Lawrence Livermore National Labora tory under contract number W-7405-ENG-48.

This document was prepared as an account of work sponsored by an agency of the United States Government. Neither the United States Government nor the University of California nor any of their employees, makes any warranty, express or implied, or assumes any legal liability or responsibility for the accuracy, completeness, or usefulness of any information, apparatus, product, or process disclosed, or represents that its use would not infringe privately owned rights. Reference herein to any specific commercial products, process, or service by trade name, trademark, manufacturer, or otherwise, does not necessarily constitute or imply its endorsement, recommendation, or favoring by the United States Government or the University of California. The views and opinions of authors expressed herein do not necessarily state or reflect those of the United States Government or the University of California, and shall not be used for advertising or product endorsement purposes. 
GEM TN-93-510

\title{
Cathode Strip Chamber Interface with Support Structure for SSC GEM Detector Muon Subsystem
}

F.C. Belser,

J.W. Clements, F.R. Holdener, J.A. Horvath, S.M. Pratuch, C.R. Wuest Lawrence Livermore National Laboratory, Livermore, CA

F. Nimblett, J. Paradiso, P. Sebelius

Charles Stark Draper Laboratories, Cambridge, MA

J. Antebi, R.P. Ojdrovic, M.S. Zarghamee

Simpson Gumpertz \& Heger Inc., Arlington, MA

M. Marx

State University of New York, Stony Brook, NY

C.V. Johnson, G. Mitselmakher

Superconducting Super Collider Laboratory, Dallas, TX

December 8, 1993

\begin{abstract}
Structural design and analysis and other practical engineering considerations indicate that the 3-point, kinematic chamber support concept in the GEM Technical Design Report should be replaced by a 4-point, "partial" kinematic support design. Detector physics performance may increase due to a resulting decreased mass in the secondary support structure.
\end{abstract}




\section{Introduction}

The design for the interface between the Cathode Strip Chambers (CSC's) and Support Structure has a significant influence on the design of the secondary support structure and alignment system and a probable impact on physics performance in the GEM Muon Detector. To put this into perspective, the GEM Technical Design Report (TDR) concept ${ }^{1}$ is summarized here along with the consensus for an alternative chamber support concept.

\section{TDR Concept}

Each CSC is supported at four symmetric points, "hard" mounted using two cross beams spanning the short dimension of the chamber near the ends, as shown in Figure 1. Figure 2 illustrates the restrictions on chamber support points due to the overlap (circumferential direction) of adjacent chambers. The ends of adjacent chambers are supported by a common, secondary support structure ("Chamber Interface Structure") as shown in Figure 3. The support points are located near the ends of the chamber, approximately 6 inches inboard on the long edges to avoid the "congestion" (projective alignment, electronics, etc.) at the ends of the chambers. The interface structure must span an axial distance of about 6 to 8 inches in addition to bridging the radial gap from support structure circumferential members to each chamber.

The initial four support points on the chamber are "collapsed" to a 3-point kinematic mount to de-couple the distortions of the chamber from any possible distortions of the support structure. One kinematic mount supports one of the cross beams attached to two of the hard mounts at one end of the chamber. The remaining two kinematic mounts support the other cross beam attached to the other two hard mounts at the other end of the chamber. "Generic" alignment requirements are summarized for all superlayers (SL) in Table 1.

\begin{tabular}{|c|c|c|c|c|c|c|}
\hline \multirow[b]{2}{*}{ Motion[a] } & \multicolumn{3}{|c|}{$\begin{array}{c}\text { Positioning } \\
\text { Accuracy, } \\
\text { Global (Local)[b] }\end{array}$} & \multicolumn{3}{|c|}{ Implementation[c] } \\
\hline & $\overline{\text { SL1 }}$ & SL2 & SL3 & Pt. \#1 & Pt. \#2 & Pt. \#3 \\
\hline $\begin{array}{l}\text { x-Translation (Tx), mm } \\
\text { z-Translation (Tz), mm } \\
\text { x-Rotation (Rx), mrad }\end{array}$ & $\begin{array}{l} \pm 6 \\
\pm 6 \\
\pm 3\end{array}$ & $\begin{array}{c} \pm 4(1.5) \\
\pm 4(1.5) \\
\pm 2(1)\end{array}$ & $\begin{array}{c} \pm 8(3) \\
\pm 8(3) \\
\pm 4(1.5)\end{array}$ & $\begin{array}{l}\text { X-actuated } \\
\mathrm{z} \text {-actuated } \\
\text { pinned }\end{array}$ & $\begin{array}{l}\text { x-actuated } \\
\text { z-slide } \\
y \text {-actuated }\end{array}$ & $\begin{array}{c}\text { x-slide } \\
\text { z-slide } \\
\text { y-actuated } \\
\text { (slave to \#2) }\end{array}$ \\
\hline z-Rotation (Rz), mrad & \pm 6 & $\pm 4(3)$ & $\pm 8(5)$ & pinned & $y$-actuated & $\begin{array}{c}y \text {-actuated } \\
\text { (slave to \#2) }\end{array}$ \\
\hline y-Rotation (Ry), mrad & \pm 3 & $\pm 2(1)$ & $\pm 4(1.5)$ & pinned & $\begin{array}{l}\text { X-actuated } \\
\text { z-slide }\end{array}$ & $\begin{array}{l}\text { X-slide } \\
\text { z-slide }\end{array}$ \\
\hline 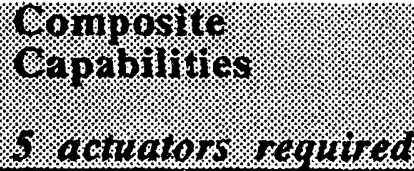 & & & & 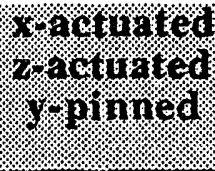 & 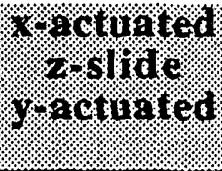 & \%ochoro. \\
\hline
\end{tabular}

a) Radial (y-translation) positional accuracy is obtained by manual adjustment during assembly and locked into place.

b) Reference GEM TN-93-336 (page 61) and GEM TN-93-397 (page 70).

c) A ball joint will be employed at point \#1. Flexure mounts or ball joints will be used at \#2 \& \#3.

Table 1: 3-Point Kinematic Mount System, Generic Requirements 


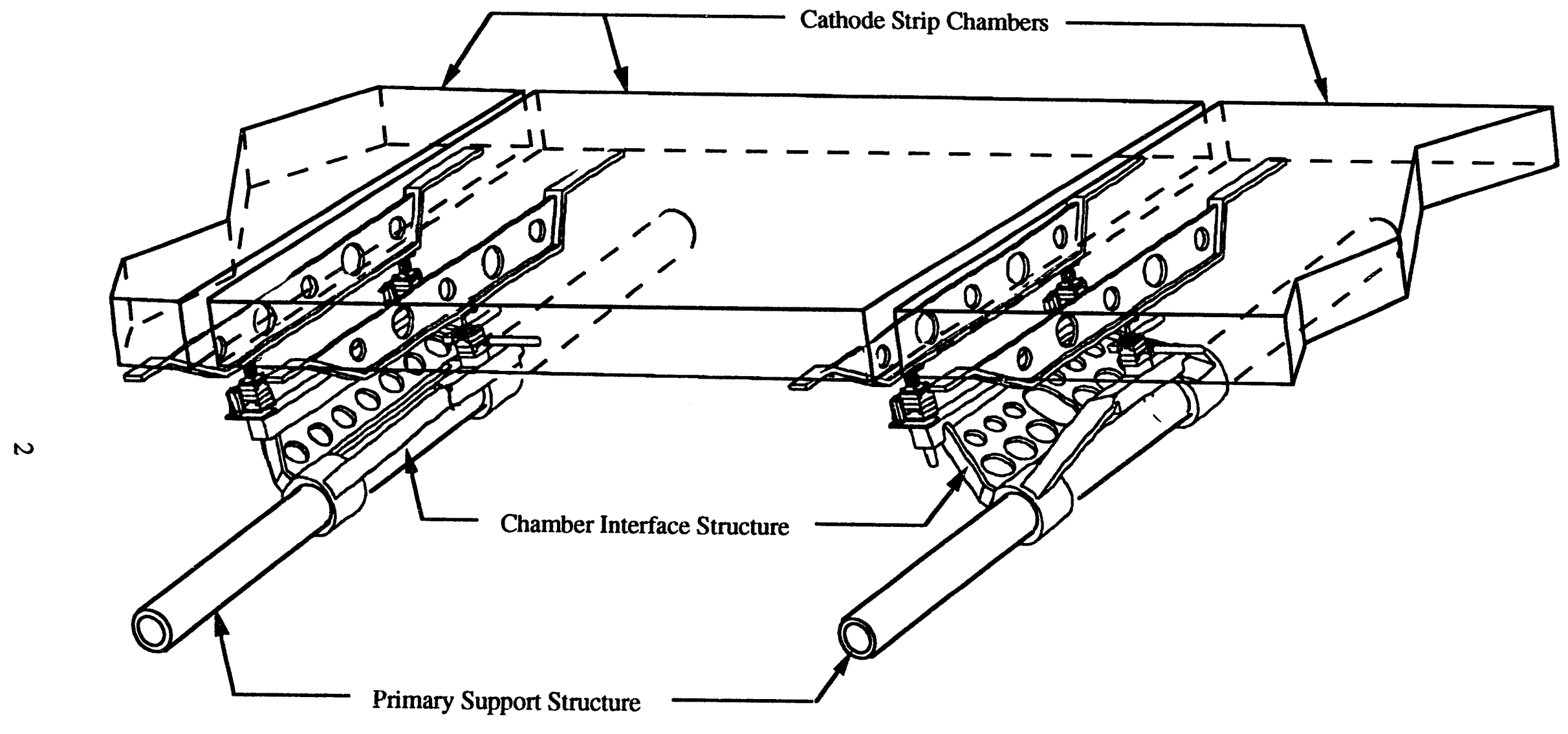

Figure 1: Chamber Interface Structure with Kinematic Mounts (Overlapping chambers deleted for clarity) 


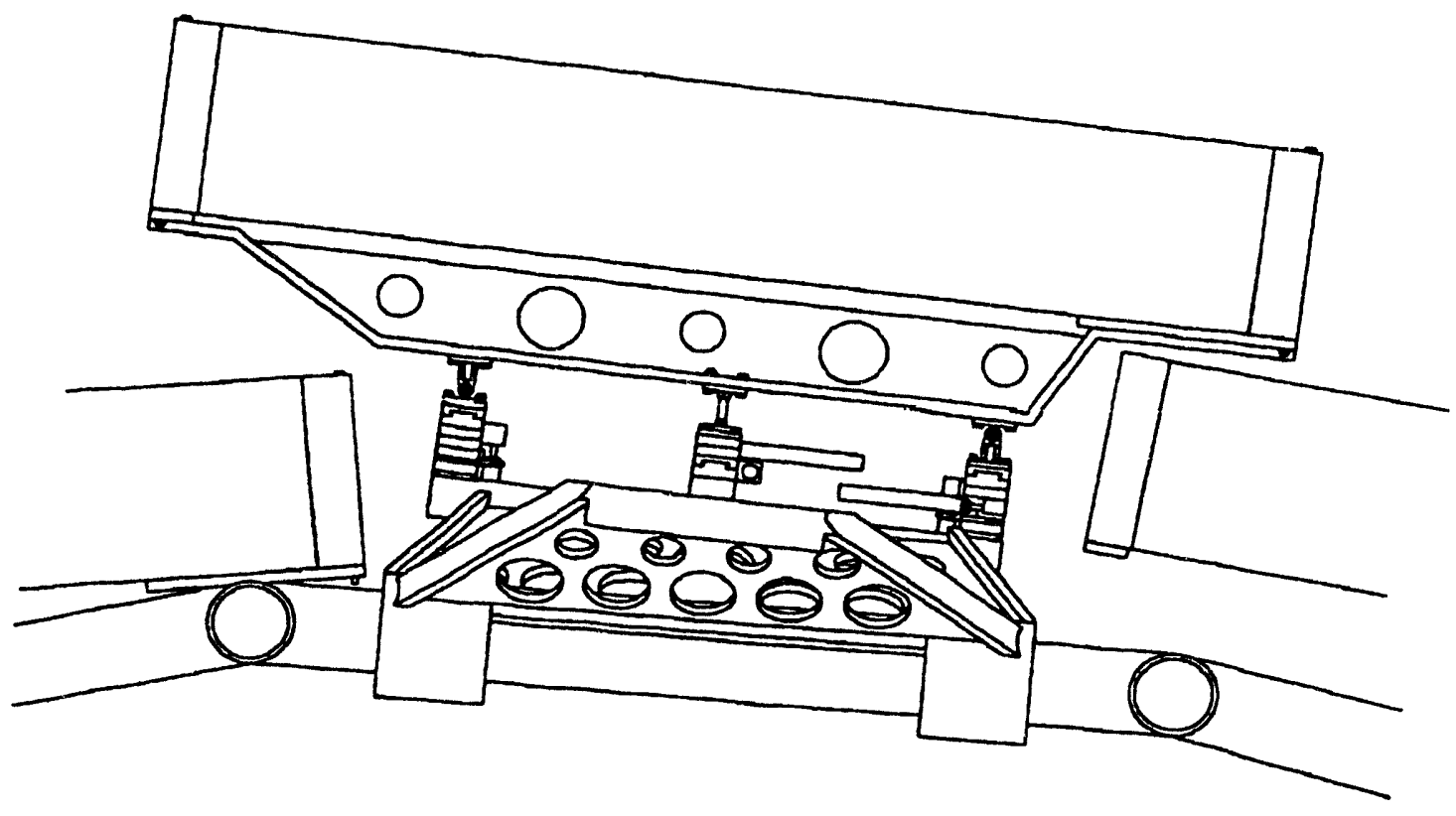

Figure 2: End View

Adjacent chambers overlap in the circumferential direction

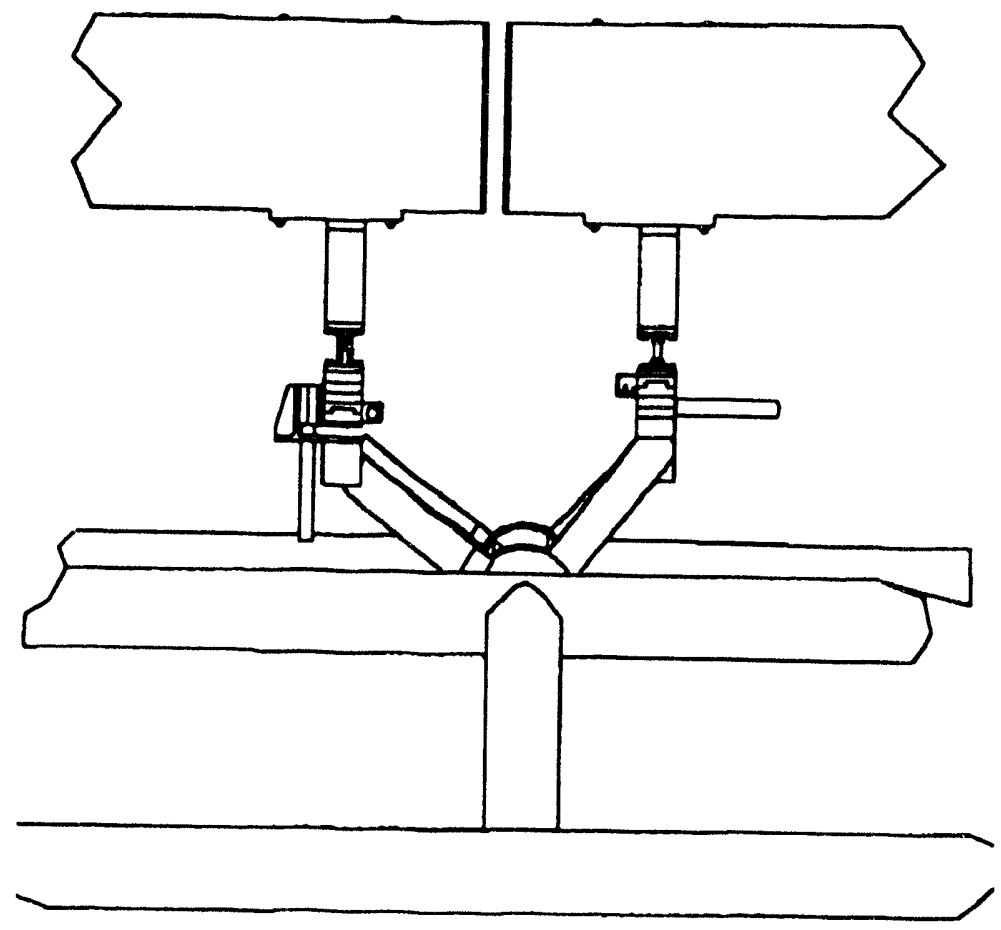

Figure 3: Side View

Adjacent chambers are supported by a common support structure 
Each of the three kinematic mounts consist of a moment de-coupling mechanism (i.e. a pin mechanism such as a ball joint) and a combination of release mechanisms (i.e. a slide mechanism such as a ball-bearing slide or a flexure mount) that function in the plane of the chamber. The selection of "in-plane" release mechanisms among the three kinematic mounts is designed to accommodate dimensional changes in the chamber (due to thermal expansion/contraction, gravitational sag, and miscellaneous utility loads) without stressing the chamber structure. Similarly, all support structure differential movements between chamber kinematic mounts are de-coupled from the chamber by these mechanisms.

The coordinate system used to describe all translations and rotations of a chamber, in relation to the 3-point kinematic mount system, is shown in Figure 4.

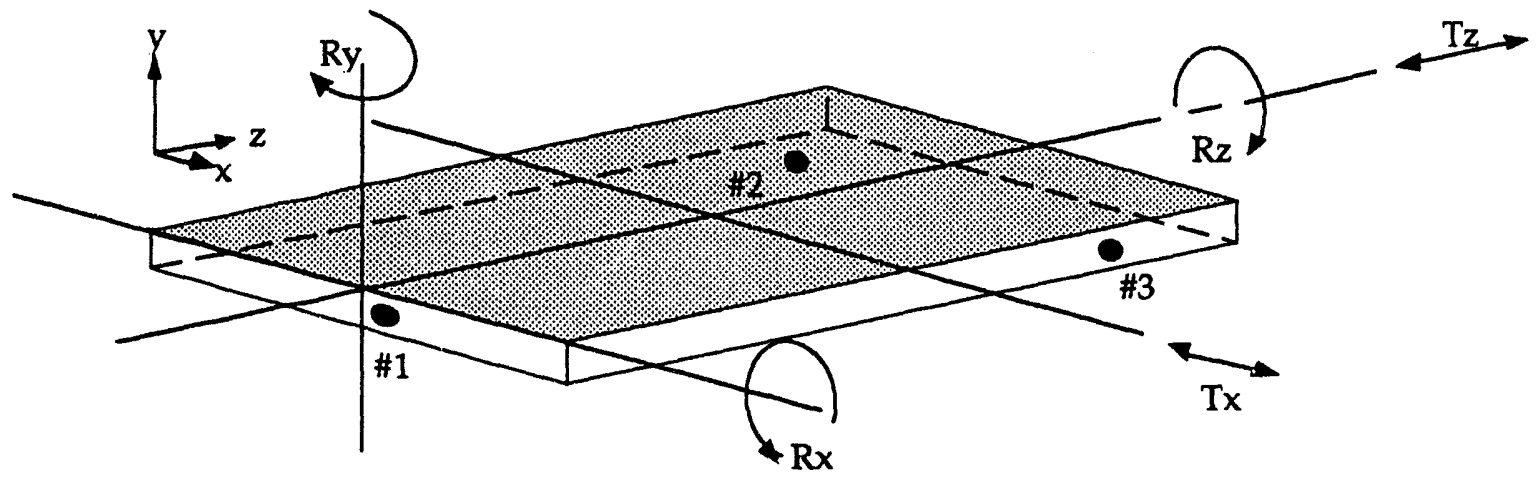

Figure 4: Coordinate System

In summary, the kinematic mounts essentially ride on top of five positioning actuators. Remote actuators may be incorporated to allow repositioning of the chamber local coordinate system during periods of restricted or prohibited access to the detector.

The complexity (and cost) of alignment hardware can be minimized by eliminating possibly redundant actuated chamber motions. Chambers in the three superlayers require only relative alignment to each other. Therefor, one scenario would be to "fix" chambers in the middle superlayer (SL2) and provide only those actuated motions required in the inner (SL1) and outer (SL3) superlayer chambers to provide adequate relative alignment. The alignment requirements for SL3 in t.is case are summarized in Table 2.

\begin{tabular}{|c|c|c|c|}
\hline \multirow{2}{*}{$\begin{array}{l}\begin{array}{l}\text { Motion for Outer } \\
\text { Superlayer (SL3) }\end{array} \\
\end{array}$} & \multicolumn{3}{|c|}{ Implementation } \\
\hline & Pt. \#1 & Pt. \#2 & Pt. \#3 \\
\hline $\mathrm{x}-, \mathrm{z}-$ Rotation $(\mathrm{Rx}, \mathrm{Rz})$ & pinned & y-actuated & $\begin{array}{c}\mathrm{y} \text {-actuated } \\
\text { (slave to \#2) }\end{array}$ \\
\hline y-Rotation (Ry) & pinned & $\begin{array}{l}\text { x-actuated } \\
\text { z-slide }\end{array}$ & $\begin{array}{l}\text { X-slide } \\
\text { z-slide }\end{array}$ \\
\hline 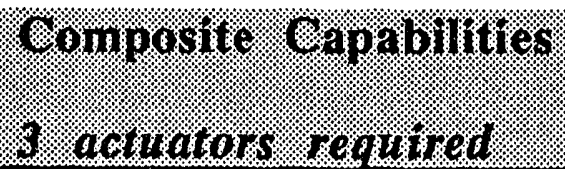 & orinned & 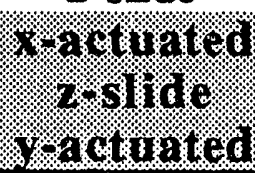 & 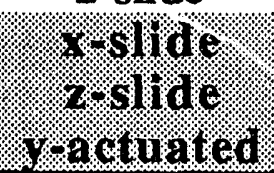 \\
\hline
\end{tabular}

Table 2: Minimum Alignment Requirements 
The minimized alignment requirements for the barrel section chambers in this scenario are summarized in Table 3.

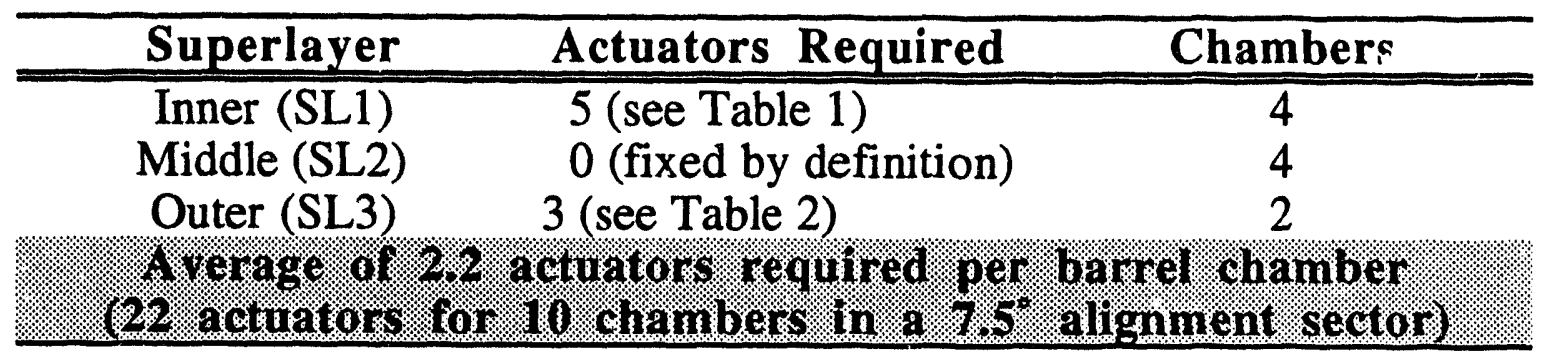

Table 3: "Composite" Alignment Requirements - Barrel Section

Note that in this case, an average of only 2.2 actuators per barrel chamber are required instead of the 5 actuators for the "generic" case in which each chamber is treated as an individual. The maximum and minimum strategies for deployment of actuated chamber motions (number and locations based on the perceived needs and assumptions of the TDR concept) were presented at the P.A.C. Review on May 26, 1993.

\section{Alternate Concept}

The Muon Chambers are supported at four symmetric locations using a "partial" kinematic mounting technique at each point. The supports are located at the ends of the chamber to take advantage of a more or less direct radial support from the circumferential members of the support structure. The supports are also located as close to the corners as possible, limited only by other genmetric constraints, as shown in Figure 5.

Each of the four "par " kinematic mounts consist of a moment de-coupling mechanism (i.e. a pin mechanism such as a ball joint) and a combination of release mechanisms (i.e. a slide mechanism such as a ball-bearing slide or a flexure mount) that function in the plane of the chamber. Since the chamber is "fixed" in the direction normal to the face of the chamber at four points instead of three, a true kinematic mount is not achieved. Potentially, one of the four support points does not lie in the same plane defined by any combination of the remaining three support points. This may be produced during chamber installation and/or distortions of the support structure after installation. Therefore, the "out-of-plane" support point produces a distortion in the chamber in addition to those produced by thermal gradients, gravitational sag, and miscellaneous utility loads.

Again, the selection of "in-plane" release mechanisms among the four "partial" kinematic mounts is designed to accommodate dimensional changes only in the plane of the chamber (due to thermal expansion/contraction, gravitational sag, etc.). Similarly, any "in-plane" differential movements of the support structure are de-coupled from the chamber by these mechanisms. However, any "out-of-plane" differential movements of the support structure are directly coupled thus causing additional distortion of the chamber. (Note that such outof-plane differential movements can be the results of temperature variations and ground vibrations; gravity and installation out-of-plane deformations do not change with time.)

Remotely operated actuators are not required. Calculated 2,3 static and dynamic deflections indicate that the SG\&H support structure design can maintain individual chambers within the required "operating" alignment tolerances after assembly and initial alignment. 


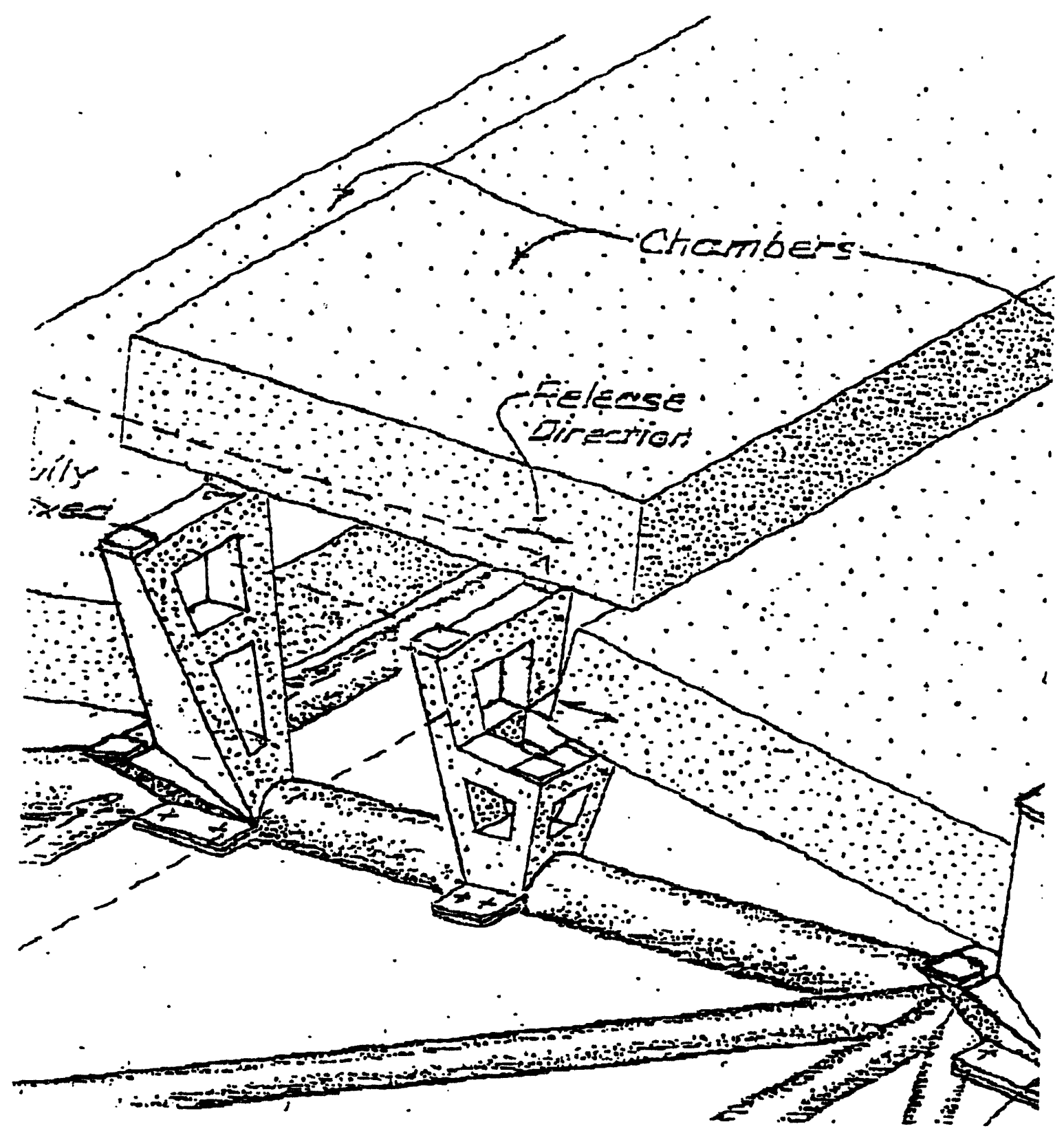

Figure 5: Barrel Chamber Mounting System

\section{Comparison of Concepts}

Both concepts initially provide support for each chamber at four points. However, the means and degree to which kinematic de-coupling is accomplished differs. There are two main issues to focus on when discussing how to support the chambers within the support structure: 3-point kinematic vs. 4-point "partial" kinematic chamber mounting and endpoint vs. 1/4-point chamber support. These issues potentially affect physics performance by influencing the mass of the support structure and alignment uncertainty. 


\section{3-point kinematic vs. 4-point "partial" kinematic chamber mounting}

A 3-point "true" kinematic chamber mount is the optimum design for isolating the chamber from all possible distortions occurring within the support structure during assembly and/or during experiment operation. This approach was taken, prior to the time of the P.A.C. Review, given the perceived uncertainties for the TDR baseline support structure design.

Even though the chamber is completely de-coupled from the support structure, there are other potential problems associated with any practical implementation of a 3-point kinematic chamber mounting scheme. Mehdi Zarghamee (SG\&H) has correctly pointed out that the 3-point mount would allow an end-to-end twisting of the chamber at some chamber locations within the support structure due to self weight (gravity). This is caused by the non-symmetric support of the two chamber cross beams by the three kinematic mounts. The chamber center of gravity is cantilevered out from the rotation points (ball joints) on the kinematic mounts. The chamber cross beam supported by the single kinematic mount (located at the center of the beam), is free to rotate w.r.t. the cross beam at the other end of the chamber which is prevented from rotating by two kinematic mounts. The calculated effect is up 50\% of the allowable chamber rotation at some locations in the detector assembly (" 3 o'clock" and " 90 'clock" chamber positions in SL3 relative to SL1). This is yet another source of uncertainty in overall sagitta correction.

Another practical design problem is the attachment between the ends of the chamber cross beams and the edge of the chamber. The design presented to the P.A.C. Review shows each end of the cross beam reduced to relatively thin "straps" in order to make it through the chamber overlap region to the edge of the chamber. This design had not been pursued beyond the concept presented and may not be sufficiently stiff. The cross beams, as an additional structural element between the chamber and kinematic mounts, must be carefully designed to ensure that additional chamber positional errors are not introduced which adversely affect sagitta correction. Dynamic structural responses had not been analyzed for this design.

With the SG\&H support structure design, the chambers are attached at the ends, inboard of the corners, to achieve rigid mounting more or less directly to the circumferential structural members. This approach avoids the chamber overlap region. Although this is a straight forward design utilizing a minimum of secondary support structure (and hence minimum mass), the chambers are supported at four points in a "partial" kinematic fashion.

The resulting shape of a chamber supported at four points with one support being "out-ofplane" of the other three was calculated ${ }^{4}$. Assuming that each chamber corner is connected to one of the supports, all edges remain straight to within 2.0 microns accuracy for an imposed single corner displacement of 1 millimeter. Thus, the chamber will distort into a simple, predictable shape directly proportional to the amount the one corner is displaced relative to the other three. If the support structure is "locally" stable (chamber level) within a few tens of microns or less, then the 4-point mount would introduce a small, predictable additional error in sagitta correction. Although the chambers are not supported exactly at the corners but instead in-board along the short edge, the difference should not be significant.

\section{End-point vs. 1/4-point chamber supports}

From the "chamber point of view", the difference between the two methods is the amount of gravitational sag allowed. The "minimize the sag so you don't have to worry about it" 
approach uses the 1/4-point supports. The "let it sag and correct the data" approach uses end-supports. The TDR baseline incorporates the later, i.e. end supports.

The so called 1/4-point support method (actually located $22.3 \%$ of the chamber length in from each end for a uniform load distribution) is optimum as it limits gravitational sag to a factor of 48.6 less than that produced by end supports $(-1 \mathrm{~mm}$ for the longest barrel chamber) 4,5 . In fact, 1/4-point supports keep chamber sag well within the 200 micron capability of the sagitta correction technique.

End supports require that the chamber deflection be predictable to within the 200 micron sagitta correction limit. Variation of chamber material properties, chamber utility system dead weight distribution, fabrication and assembly processes, and mounting will determine the magnitude of that uncertainty. Currently, predicting a $1 \mathrm{~mm}$ gravitational sag to within $10 \%$ (100 microns) would seem a reasonable assumption, but this needs to be verified with tests of actual materials and chamber assemblies. Thus, there remains a potential physics performance issue affecting alignment accuracy if chamber sag can not be predicted to approximately $10 \%$ or better.

However, the "chamber point of view" is not the entire story. End supports make optimum use of both the TDR and SG\&H support structure designs by supporting the chambers more or less directly from the circumferential structural members. The 1/4-point support method would require additional secondary support structure to "reach in" to the chamber, thus adding additional unwanted mass to the Muon Detector. Thus, there is a potential physics performance issue which encourages minimal mass in the support structure. Physical access inside the support structure may also be compromised with the additional secondary structure.

There is a trade-off between alignment uncertainty on the one hand and additional mass in the detector on the other, both impacting on physics performance. Physical access issues will impact costs (assembly labor and productivity) more directly.

\section{Chamber Structural Integrity}

The distortions that might be imposed on the chambers under the scenarios discussed above would result in low stresses within chamber components. In fact, the only concern remaining is creep under load as this could affect alignment over time. Calculated stresses $4,5,6$ are a few tens of psi at most in the TDR baseline concept which is not a concern for the materials being contemplated (plastics and composites) as long as the service temperature remains around room temperature.

As the chamber design continues to evolve, these assumptions will need to be reviewed to make sure we do not "design ourselves into a corner" with a creep problem. In addition, materials and prototype assemblies will need to be tested, as they become available, to verify the calculations prior to mass production.

One practical requirement for chamber design is to use the edges of the chamber for mounting and supports. The edges of each panel are already reinforced in order to tie individual panels together into a more rigid assembly. The chamber faces, interior to the edges, are not suitable for mounting. 


\section{Conclusions}

The chamber as a structure can accommodate any of the proposed support methods without being subjected to unacceptable stresses. (This assumes that the out-of-plane distortions imposed on a chamber using the 4-point "partial" kinematic mount are limited to a few millimeters.) It appears that neither of the proposed concepts introduces significant, uncorrectable sagitta error given the foregoing assumptions.

There are practical engineering considerations that might drive the design selection towards a 4-point "partial" kinematic mount concept with the support points located at the chamber ends. The secondary support structure is more straight forward in that the corners of the chamber are tied more or less directly to the circumferential members of the main support structure. (In the event that a hybrid axial-projective alignment system is selected, the congested real estate between chambers, where the end supports are located, would also be simplified. If alignment remains "pure" projective, the design of the chamber supports could become more complicated.) Minimal support structure mass and probably increased accessibility also favor this design; lower cost most likely results.

Practical engineering considerations aside, the following physics issues had to be resolved to determine whether there were compelling physics reasons to select one chamber support method over the other:

1. Does "pure" projective or "hybrid" axial-projective alignment favor one or the other proposed chamber support methods w.r.t. sagitta correction accuracy?

2. Is a chamber sag of millimeter or more in the center really acceptable if the sag can be predicted to $10 \%$ or better (end vs. $1 / 4$ point support)?

3. Are the cumulative effects of all the minor uncertainties in sagitta error inherent in the various design features understood sufficiently to make a selection?

The foregoing discussion was circulated prior to holding a video conference 7 where the outstanding issues were discussed. It was agreed that:

1. There are no compelling physics reasons to select one or the other support concept due to requirements of any particular alignment concept (pure projective of hybrid axial-projective).

2. A sag of approximately 1 millimeter at the center of the largest chamber is acceptable as long as it can be predicted to $10 \%$ or better. However, this must be verified with tests on pre-production chambers.

3. The cumulative effect of all the minor uncertainties in sagitta error are accounted for and understood. Again, this must be verified by tests.

4. The 4-point "partial" kinematic support appears to be "dynamically" superior to the 3-point kinematic mount system, but further analytical verification is required. (Sagitta correction techniques cannot handle dynamic chamber movement i.e. vibration.)

5. A creep problem with chamber materials would favor the 1/4-point supports but this is not likely a problem. Creep tests are needed to verify this assumption for materials where data does not already exist. 


\section{"New Baseline"}

The consensus opinion at the video conference was to proceed with a 4-point "partial" kinematic support design located at the ends of the chamber. This decision was arrived at for practical engineering considerations, a possible gain in physics performance (lower mass), and being that there were no compelling physics reasons not to do so.

Discussions before and after the video conference pointed to a possible interference between cathode electronics and end-mounted chamber supports. A previous proposal suggested moving the cathode electronics to the large chamber faces ("motherboard" face or opposite face). It is highly desirable to have the electronics mounted anywhere else but the ends, as with the TDR concept, so that the gap betweeti chambers could be reduced and muon detector coverage increased with a resulting increase in physics performance. Initial layouts showed that electronics packing on the surface of the chamber (near the ends) would be extremely tight, if not nearly impossible, with or without setting aside some of that real estate for the chamber mounts (3-point or 4-point); this is especially critical for the smaller chamber sizes.

Therefore, the decision on the "new baseline" chamber support design may require further review pending the outcome of further design studies for the layout of chamber mounts and cathode electronics on the chamber surfaces.

NOTE: Reference documents 3, 4, and 6 were not available at the time the decision was made to change the "baseline" chamber support design. However, the information in the documents was either available during the decision-making process or was generated as a result of the decision in order to verify assumptions; they are included here for completeness. 


\section{References}

1. GEM TN-93-262, GEM Technical Design Report, April 30, 1993

2. GEM TN-93-519, Monolithic Integrated Concepts for Muon Subsystem Structures, June 8, 1993

3. GEM TN-93-520, Dynamic Sagitta Error of Muon Subsystem Structure, September 28, 1993

4. GEM TN-93-494, Engineering Analysis of Large Precision Cathode Strip Chambers for GEM, October 21, 1993

5. GEM TN-93-350, Gravity Sag of Sandwich Panel Assemblies as Applied to Precision Cathode Strip Chamber Structural Design, July 12, 1993

6. GEM TN-93-460, Comparison of Gap Frame Designs and Materials for Precision Cathode Strip Chambers, September 9, 1993

7. Video Conference with B. Barish and M. Gamble (SSCL); J. Antebi and $M$. Zarghamee (SG\&H); F. Nimblett, J. Paradiso, and P. Sebelius (CSDL), C. Belser, J. Horvath, and C. Wuest (LLNL), July 28, 1993 


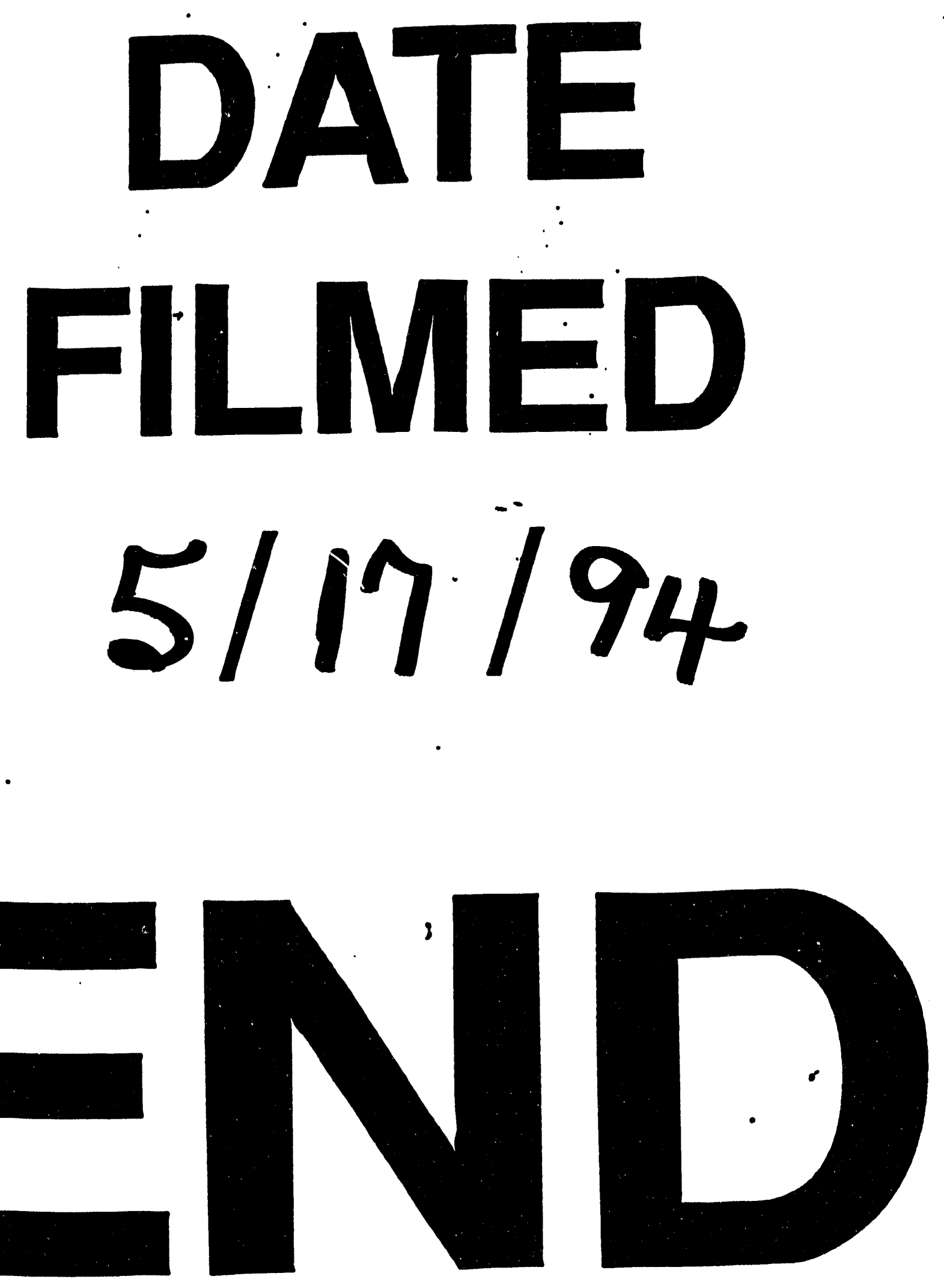


